\title{
Predicting the Temperature and Reactant Concentration Profiles of Reacting Flow in the Partial Oxidation of Hot Coke Oven Gas using Detailed Chemistry and a One-dimensional Flow Model
}

Srinivas Appari ${ }^{1}$, Ryota Tanaka ${ }^{1}$, Chengyi $\mathrm{Li}^{2}$, Shinji Kudo ${ }^{1}$, Jun-ichiro Hayashi ${ }^{1,2,3}$, Vinod M Janardhanan ${ }^{4}$, Hiroaki Watanabe ${ }^{5}$, and Koyo Norinaga ${ }^{1,2, *}$

${ }^{1}$ Institute for Materials Chemistry and Engineering, Kyushu University, Kasuga 816-8580, Japan

${ }^{2}$ Interdisciplinary Graduate School of Engineering Sciences, Kyushu University, Kasuga 816-8580, Japan

${ }^{3}$ Research andEducation Center of Carbon Resources, Kyushu University, Kasuga, 816-8580, Japan

${ }^{4}$ Department of Chemical Engineering, Indian Institute of Technology Hyderabad, Hyderabad, Telangana, 502 205, India

${ }^{5}$ Energy Engineering Research Laboratory, Central Research Institute of Electric Power Industry (CRIEPI), 2-6-1 Nagasaka, Yokosuka, Kanagawa 240-0196, Japan

*Corresponding author. norinaga@cm.kyushu-u.ac.jp Institute for Materials Chemistry and Engineering, Kyushu University, Kasuga 816-8580, Japan.

\begin{abstract}
A numerical approach is presented for predicting the species concentrations and temperature profiles of chemically reacting flow in the non-catalytic partial oxidation of hot coke oven gas (HCOG) in a pilot-scale reformer installed on an operating coke oven. A detailed chemical kinetic model consisting of 2216 reactions with 257 species ranging in size from the hydrogen radical to coronene was used to predict the chemistries of HCOG reforming and was coupled with a plug model and onedimensional (1D) flow with axial diffusion model. The HCOG was a multi-component gas mixture derived from coal dry distillation, and was approximated with more than
\end{abstract}


40 compounds: $\mathrm{H}_{2}, \mathrm{CO}, \mathrm{CO}_{2}, \mathrm{CH}_{4}, \mathrm{C}_{2}$ hydrocarbons, $\mathrm{H}_{2} \mathrm{O}$, aromatic hydrocarbons such as benzene and toluene, and polycyclic aromatic hydrocarbons up to coronene. The measured gas temperature profiles were reproduced successfully by solving the energy balance equation accounting for the heat change induced by chemical reactions and heat losses to the surroundings. The approach was evaluated critically by comparing the computed results with experimental data for exit products such as $\mathrm{H}_{2}, \mathrm{CO}, \mathrm{CO}_{2}$, and $\mathrm{CH}_{4}$, in addition to the total exit gas flow rate. The axial diffusion model slightly improves the predictions of $\mathrm{H}_{2}$, $\mathrm{CO}$, and $\mathrm{CO}_{2}$, but significantly improves those of $\mathrm{CH}_{4}$ and total exit flow rate. The improvements in the model predictions were due primarily to the improved temperature predictions by accounting for axial diffusion in the flow model.

Keywords: Reforming; Partial oxidation; Coke oven gas; Synthesis gas; Detailed chemistry

\section{Introduction}

Efficient, cost-effective technologies to reform hydrocarbon fuels are needed to encourage future $\mathrm{H}_{2}$ utilisation. One promising source of $\mathrm{H}_{2}$ is coke oven gas (COG), which is a by-product in coke production, emitted at 300-350 $\mathrm{Nm}^{3}$ per ton of coal [1]. The hot coke oven gas (HCOG) released from a coke oven is a multicomponent gas mixture, containing tarry compounds and steam in addition to $\mathrm{H}_{2}, \mathrm{CO}, \mathrm{CO}_{2}$, and $\mathrm{CH}_{4}$ [2-4]. The tar contains mono- and polycyclic aromatic hydrocarbons and comprises approximately $30 \mathrm{wt} \%$ of the HCOG [5]. In the conventional coke-making process, the HCOG is quenched to remove condensing components such as tar and water. The dry COG is used as fuel in steelworks and contains $54-59 \mathrm{~mol} \% \mathrm{H}_{2}$ and $24-28 \mathrm{~mol}^{\circ} \mathrm{CH}_{4}$ 
[6]. The amount of $\mathrm{H}_{2}$ in dry COG can be amplified by catalytic [7,8] or non-catalytic $[9,10]$ reforming by $\mathrm{CO}_{2}$ or steam. Clean (tar-free) gas production by direct reforming of HCOG (without a cooling process) has been studied as an efficient process by utilising the HCOG heat $[2,11,12]$. The products from the partial oxidation of HCOG reforming are also suitable as feedstock for methanol production [13]. HCOG typically contains $0.3 \mathrm{wt} \% \mathrm{H}_{2} \mathrm{~S}$ [11], which can deactivate the reforming catalysts. Catalytic deactivation by sulphur compounds [14,15] and coke [16-18] is unavoidable; these problems make non-catalytic reforming an attractive option for HCOG reforming. Non-catalytic partial oxidation is conducted in a reactor by feeding HCOG and air in a sub-stoichiometric ratio, which results in temperature $>1500 \mathrm{~K}$ [11]. The high temperature and steam produced by the partial oxidation process are used to sustain the endothermic reforming reactions $[19,20]$. There are many commercial and technical benefits of applying the numerical simulations based on the reliable reactor models, which helps in designing the reactor and optimizing the process operation. Prediction of the axial temperature profile without using empirical information is important for the design and operation of an exothermic partial oxidation process. Many flow reactor simulations have been carried out based on pre-existing/empirical temperature profiles $[13,21,22]$ or with assumptions such as isothermal and negligible axial diffusion. For example, hydrocarbon pyrolysis experiments have been simulated numerically with a detailed kinetic model [23] coupled with a plug flow reactor model [21], where empirical temperature profiles were used as input for plug flow simulations. Sheng et al. [22] emphasised the importance of gas-phase kinetics in anode channel solid oxide fuel cells and used a model with an empirical axial temperature profile. Previously, we approximated the experimental axial temperature profile of a HCOG reformer as an 
empirical polynomial, validating it based on an empirical temperature profile with the assumption of negligible axial diffusion [13]. These empirical temperature profiles were developed based on limited temperature measurements and might introduce uncertainty in model predictions. Axial diffusion causes a degree of mixing in the axial direction in real reactors, the plug flow reactor model is appropriate when this effect is sufficiently small that it can be ignored. Diffusion can occur because of the concentration gradient in the axial direction. It is usually less important than bulk flow in most practical systems. However, the inclusion of axial diffusion in plug flow reactor models may give information about the deviation from ideality, which is generally present in real reactor systems [24].

The primary importance of this paper is that it estimates the axial temperature profiles for the partial oxidation of HCOG using a new numerical approach. The heat losses to the surroundings and non-ideality of the plug flow with axial diffusion are accounted for in numerical simulations. An existing kinetic model proposed by Richter and Howard [25] is used to simulate the pilot-scale HCOG reforming. The kinetic model consists of more than 2000 elementary steps, such as reactions, and is capable of accurately capturing phenomena that occur in the gas-phase reactions. The kinetic model is validated with experimental observations of the major components, such as $\mathrm{H}_{2}$, $\mathrm{CO}, \mathrm{CO}_{2}$, and $\mathrm{CH}_{4}$, and the total dry gas flow rate, in addition to the axial temperature profiles of 19 pilot-scale runs.

\section{Pilot-scale Test of HCOG Reforming}

A pilot-scale test plant for HCOG reforming with partial oxidation was installed on a platform of an operating coke oven at Kitakyushu city, Japan. The HCOG was 
collected from three coke chambers and introduced to the reformer at a temperature range of 625- $665 \mathrm{~K}$ together with $\mathrm{O}_{2}$ at room temperature. The HCOG flow rate was adjusted by the dampers, which were placed at the top of the coke oven chambers. HCOG was fed into a horizontal cylindrical section (0.6-m ID and $3.24 \mathrm{~m}$ long) at flow rates from 45 to $63.9 \mathrm{Nm}^{3} / \mathrm{h}$ and was partially oxidized by $\mathrm{O}_{2}$ (from 14.2 to 19.4 $\mathrm{Nm}^{3} / \mathrm{h}$ ) from the four nozzles near the inlet. The reformer was operated at atmospheric pressure. Temperature profiles were measured with thermocouples inserted vertically at different positions inside the reformer. The gas compositions at the reformer inlet and outlet were measured using an online gas chromatography, and condensing products such as water and tar were sampled and analysed offline. The details of the pilot-scale test procedure have been reported elsewhere [13]. Pilot-scale measurements of 19 runs were used to validate the numerical approach.

The HCOG is a multicomponent gas mixture, particularly it contains around $30 \mathrm{wt} . \%$ tar compounds that include various mono and polycyclic aromatic compounds. Due to this nature, reforming of HCOG by partial oxidation is a complex process. Chemistry and kinetics are essential to understand the complex reforming process. HCOG contains large fractions of $\mathrm{CH}_{4}$, and $\mathrm{H}_{2}$, and these species are participating in combustion reactions with $\mathrm{O}_{2}$, thereby accelerating the reforming of the tar by steam. The water produced from the $\mathrm{CH}_{4}$ and $\mathrm{H}_{2}$ oxidations, and reverse water- gas shift reaction, in addition to these water formation reactions, HCOG also contains some fraction of $\mathrm{H}_{2} \mathrm{O}$, may induce reforming reactions. Most likely, these exothermic oxidation reactions were dominating at the reactor entrance, and later endothermic reforming reactions are taking place. 


\section{Modelling Approach}

A one-dimensional flow reactor model coupled with heat losses to the surroundings was used to simulate the HCOG reforming pilot-scale tests. The real reactor is shown schematically in Figure 1. For the numerical simulations, the flow reactor was idealised as a 3.2-m-long tube reactor with a constant inside diameter of $0.6 \mathrm{~m}$.

\subsection{Plug Flow Model}

A plug flow reactor model was implemented by assuming ideal gas behaviour and constant pressure. The total continuity equation is written as

$$
\frac{d\left(\rho u A_{c}\right)}{d z}=0
$$

The species transport in a reactor model is described as

$$
\rho u A_{c} \frac{d Y_{k}}{d z}=A_{c} \dot{\omega}_{k} W_{k}, \quad k=1, \ldots, K_{g},
$$

and the energy equation considering heat loss to the surroundings is written as

$$
\rho u C_{p} \frac{d T}{d z}-\frac{d}{d z}\left(\lambda \frac{d T}{d z}\right)+\sum h_{k} \dot{\omega}_{k} W_{k}=U_{\text {loss }}\left(T-T_{\text {amb }}\right) \frac{A_{s}}{A_{c}} .
$$

In these equations, $\rho$ is the density in $\mathrm{kg} / \mathrm{m}^{3}, u$ is the velocity in $\mathrm{m} / \mathrm{s}, Y_{k}$ is the mass fraction of species $k, \lambda$ is the thermal conductivity of the mixture in $\mathrm{J} /(\mathrm{m} \cdot \mathrm{s} \cdot \mathrm{K}), h_{k}$ is the specific enthalpy in $\mathrm{J} / \mathrm{kg}, \omega_{k}$ is the molar production rate of species $\left(\mathrm{mol} /\left(\mathrm{m}^{3} \cdot \mathrm{s}\right)\right), W_{k}$ is the molecular weight of species $k$ in $\mathrm{kg} / \mathrm{mol}, U_{\text {loss }}$ is the overall heat transfer coefficient relating the heat loss from the reactor to the atmosphere in $\mathrm{J} /\left(\mathrm{m}^{2} \cdot \mathrm{s} \cdot \mathrm{K}\right), A_{s}$ is the surface area per unit length, $A_{c}$ is the cross-sectional area, $T$ is the gas phase temperature, and $T_{a m b}$ is the atmospheric temperature. 


\subsection{D- Flow Model with Axial Diffusion}

The total continuity equation was the same as above, and species transport in a reactor model with axial diffusional resistance is described as

$$
\rho u \frac{d Y_{k}}{d z}+\frac{d j_{k}}{d z}=\dot{\omega}_{k} W_{k}, k=1, \ldots, K_{g},
$$

where $j_{k}$ is the mass flux of species $\left(\mathrm{kg} / \mathrm{m}^{2} \cdot \mathrm{s}\right)$ given by

$$
j_{k}=-\rho D_{k m} \frac{d Y_{k}}{d z}
$$

The energy equation that considers the heat loss from the reactor wall to the atmosphere is represented as

$$
\rho u C_{p} \frac{d T}{d z}-\frac{d}{d z}\left(\lambda \frac{d T}{d z}\right)+\frac{d}{d z} \sum_{k} j_{k} h_{k}+\sum_{k} h_{k} \dot{\omega}_{k} W_{k}=U\left(T-T_{a m b}\right) \frac{A_{s}}{A_{c}}
$$

and the density is calculated from the equation of the state

$$
p \bar{w}=\rho R T .
$$

The mass fluxes are calculated in such a way that the total flux is conserved, i.e.,

$$
\sum_{k=1}^{K_{g}} j_{k}=0
$$

The diffusion coefficient is calculated using

$$
D_{k m}=\frac{1-Y_{k}}{\sum_{j \neq k}^{K_{g}} X_{j} / D_{j k}}
$$

Here, $D_{k m}$ is the diffusional coefficient of species $k$ in the mixture, and $X_{j}$ is the mole fraction of species $j$. The binary diffusion coefficient is calculated from ChapmanEnskog theory [26]. 


\subsection{De tailed Kine tic Model}

We used an existing detailed kinetic model [27] developed by Richter and Howard that consists of 2216 elementary irreversible reactions with 257 chemical species ranging in size from the smallest radical (the hydrogen radical) to the largest molecule (coronene). This mechanism was applied successfully to predict the aromatic hydrocarbon conversions in the presence of hydrogen and steam [28]. The thermodynamic data for the species involved in the mechanism and the rate constants were used without modification.

\subsection{Numerical Simulations}

A one-dimensional reactor model coupled with the detailed kinetic model was used for numerical simulations. A portion of the HCOG was sampled from the gas stream. Tarry constituents were condensed and weighed to determine the total tar concentration in HCOG which was varied from 44 to $126 \mathrm{~g} / \mathrm{Nm}^{3}$. Tar was approximated to be a mixture of 31 aromatic hydrocarbons as done in our previous works [13,29] and the abundances of the compounds were estimated based on the quantitative analysis by Kirton et al [6]. Table 1 shows the composition of the feed HCOG for numerical simulation (run 11), and those for all 19 runs are provided in the supplementary material. All of the runs of the HCOG partial oxidation experimental results were used to validate the model, not only with axial temperature profiles but also with major gas-phase species such as $\mathrm{H}_{2}$, $\mathrm{CO}, \mathrm{CO}_{2}$, and $\mathrm{CH}_{4}$. The implicit code LIMEX [30] for the plug flow model or CVODE [31] for the axial diffusion flow model was used to solve the coupled governing equations describing the numerical model. The DETCHEM ${ }^{\mathrm{PLUG}}$ [32] was partially customized and used for the plug flow simulation. Global sensitivity analysis was 
carried out for the major gas-phase species to understand the dominant and important reactions in the mechanism.

\section{Results and Discussion}

\subsection{Plug Flow Model}

A temperature measurement along the axial position of the reactor indicated that the temperature was high near the reactor inlet and decreased towards the exit. The initial increase in temperature was due to the exothermic partial oxidation, and the decreasing trend was due to the endothermic reforming. The initial simulations were performed with an ideal plug flow model [32] under adiabatic conditions, but these failed to predict the temperature profile (Figure 2). Because the reactor inlet temperature is lower than the ignition temperature of the mixture, the reaction mixture is force ignited in the numerical simulations. In this method, the reaction rates are calculated at a pre-defined ignition temperature, which results in a change in the enthalpy of the mixture so that eventually, the mixture temperature exceeds the pre-defined ignition temperature due to the exothermic reactions. Once the mixture temperature exceeds the pre-defined ignition temperature, the reaction rates are calculated using the actual mixture temperature.

Figure 2 shows the temperature profile (run 11) as a function of axial position under adiabatic conditions. When the pre-defined ignition temperature was too high, e.g., $1000 \mathrm{~K}$, the reaction rate was very high, and the gas phase temperature increased suddenly within a few centimetres of the reactor inlet; this was not captured the thermocouple measurement at near the reactor inlet, so the profile is flat. In another case, at a pre-defined ignition temperature of $850 \mathrm{~K}$, the supplied energy was not able to ignite the fuel mixture, and the predicted temperature profile showed a constant 
temperature after ignition. At an ignition temperature of $900 \mathrm{~K}$, the profile was sluggish and showed a sharp increase. This procedure optimised the ignition temperature and predicted the sharp increase and first thermocouple measurement at $950 \mathrm{~K}$, although it failed to predict the complete trend. This might be because in the actual pilot-scale reactor, there is heat loss to the surroundings, and the numerical model neglects this loss.

To capture the complete profile, heat loss to the surroundings was also considered by introducing the overall heat transfer coefficient. A DETCHEM ${ }^{\text {PLUG }}$ code [32] was partially customized to implement the heat loss from the reactor wall to the surroundings. Figure 3 shows the effect of heat losses to the surroundings at a fixed ignition temperature $950 \mathrm{~K}$. When the overall heat transfer coefficient $U_{\text {loss }}$ was zero, the predicted temperature was uniform throughout the reactor, i.e., adiabatic conditions, and the predicted temperature profile far exceeded the experimental measurements. When $U_{\text {loss }}$ was $10 \mathrm{~W} / \mathrm{m}^{2} \cdot \mathrm{K}$, more heat was lost from the reactor, and the predicted profile was far below the actual temperature profile. The predicted profile was just above the measured profile when $U_{\text {loss }}$ was $2 \mathrm{~W} / \mathrm{m}^{2} \cdot \mathrm{K}$. The experimental temperature profile (run 11 of 19 runs) was captured accurately when the overall heat transfer coefficient was $4 \mathrm{~W} / \mathrm{m}^{2} \cdot \mathrm{K}$.

\subsection{Critical Evaluation}

Figure 4 shows the model predictions with axial temperature observations of the HCOG reformer for 19 runs. All of these predictions used an overall heat transfer coefficient of $4 \mathrm{~W} / \mathrm{m}^{2} \mathrm{~K}$ and an ignition temperature of $950 \mathrm{~K}$. A large difference was observed between the predicted and measured temperature at the first thermocouple location, 
which was located at the reactor inlet. However, except at near the reactor inlet, the ratio between the predicted and measured temperature at different thermocouple locations varies from 0.95 to 1.13 and were generally within $\pm 10 \%$ error. These ratios indicate that the model well predicts the axial temperatures at different locations of the reformer except at near the reactor inlet. The parity plot between the model predictions and measured temperatures along the axial position of the reformer was provided in the supplementary material. The initial sharp rise in temperature near the reactor inlet was due mainly to the exothermic partial oxidation reactions of light hydrocarbons and $\mathrm{H}_{2}$ combustion.

Figure 5 compares the predicted dry gas mole fractions at the reactor outlet with pilot-scale reforming runs for major species such as $\mathrm{H}_{2}, \mathrm{CO}, \mathrm{CO}_{2}$, and $\mathrm{CH}_{4}$ for the 19 test runs. The range of ratios of the volume \% predicted numerically to those measured were 0.96-1.02, 1.11-1.29, 0.65-0.9, and 0.09-0.94 for $\mathrm{H}_{2}, \mathrm{CO}, \mathrm{CO}_{2}$, and $\mathrm{CH}_{4}$, respectively. Overall, the predictions were in good agreement with the pilot-scale runs. Our kinetic model does not contain $\mathrm{H}_{2}$-yielding gas-solid reactions, such as carbon deposition and soot-formation mechanisms. Many factors account for the over- and under-predictions, such as the accumulation of coke on the reactor wall. The deposition of carbon reduces the gas volume, but increases the $\mathrm{H}_{2}$ concentration.

Figure 6 compares the numerically predicted dry gas flow rates at the rector outlet with measured flow rates in the HCOG reformer. The simulation tended to overpredict the outlet flow rate, mainly due to the over decomposition of hydrocarbons induced by over-predicted temperatures near the reactor entrance. 


\subsection{Sens itivity Analys is}

In all the pilot-scale runs, $\mathrm{H}_{2}, \mathrm{CO}_{2}$, and $\mathrm{CH}_{4}$ were under predicted, whereas $\mathrm{CO}$ was over-predicted. To understand these disagreements qualitatively, a global sensitivity analysis of major gas phase species was carried out with HOMREA [33], a software package designed for homogeneous reaction systems. High sensitivity coefficients have a substantial influence on the model predictions. A positive sensitivity coefficient indicates that the reaction enhances the species production rate or slows its consumption rate, whereas a negative sensitivity coefficient indicates the opposite. Although the kinetic model contains 2216 reactions, only a few reactions were found to be sensitive for the $\mathrm{H}_{2}, \mathrm{CO}, \mathrm{CO}_{2}$, and $\mathrm{CH}_{4}$ predictions. Figure 7 shows the global sensitivity for the major gas species. Only four and 15 reactions were sensitive to the $\mathrm{CO}_{2}$ and $\mathrm{H}_{2}$ predictions, respectively, and 13 reactions to $\mathrm{CO}$ and $\mathrm{CH}_{4}$ in a complex reaction network.

Figure 7a shows the sensitive coefficients (R1-R15) for $\mathrm{H}_{2}$; reaction $\mathrm{R} 2$ was the most sensitive for the production of $\mathrm{H}_{2}$, whereas the consumption of $\mathrm{H}_{2}$ was more sensitive to reaction R1. Reaction R1 might be responsible for the under-prediction of $\mathrm{H}_{2}$ in most of the runs. The sensitivity coefficients for CO are shown in Fig. 7b. Reactions R1 and R6 were more sensitive to the $\mathrm{CO}$ production rate, whereas the $\mathrm{CO}$ consumption was influenced mostly by reactions R2 and R5. The over-prediction of CO was due mainly to reactions R1 and R6.

Figure 7c shows the sensitivity coefficients for $\mathrm{CO}_{2}$. Reactions $\mathrm{R} 1$ and $\mathrm{R} 18$ were more sensitive for $\mathrm{CO}_{2}$ consumption, whereas the $\mathrm{CO}_{2}$ production was influenced more by reactions $\mathrm{R} 2$ and $\mathrm{R} 3$. The plug flow model predicted $\mathrm{CO}_{2}$ values lower than the experimental measurements due mainly to reactions R1 and R18. The sensitivity 
coefficients for $\mathrm{CH}_{4}$ are shown in Fig. 7d. The consumption of $\mathrm{CH}_{4}$ was more sensitive to reactions $\mathrm{R} 8$ and $\mathrm{R} 11$, which might be responsible for the under-prediction of $\mathrm{CH}_{4}$ in all of the runs. Reaction R12 was sensitive to the production of $\mathrm{CH}_{4}$. However, the activation energy of reaction R8 was very high (439 kJ/mol), which indicates that the reaction was the most temperature sensitive. The kinetic model predicted a higher temperature than the actual value at near the reactor inlet, which might cause greater consumption of $\mathrm{CH}_{4}$ via partial oxidation, which is another reason for the underprediction of $\mathrm{CH}_{4}$. Nevertheless, the under- and over-predictions of gas-phase species composition were due mainly to the over-predicted reaction temperatures and deviation from ideal behaviour. Overall, the under-prediction of $\mathrm{H}_{2}$ and $\mathrm{CO}_{2}$, and over-prediction of CO were greatly influenced by reaction R1, and reactions R8 and R11 were responsible for the under-prediction of $\mathrm{CH}_{4}$.

\subsection{Flow Model with Axial Diffusion}

The ideal plug flow reactor models neglect axial diffusion. However, the presence of axial diffusion causes a degree of mixing in the axial direction of real reactors. Therefore, neglecting the axial diffusion term in a plug flow reactor model can lead to uncertainty in the model predictions. The predicted temperature rose suddenly near the reactor inlet in the absence of diffusion flow resistance (Figure 2). This behaviour results mainly from the exothermic $\mathrm{H}_{2}$ combustion. The high diffusion coefficient of $\mathrm{H}_{2}$ [34] might be responsible for a sharp rise in temperature, as it was present in significant amounts in the HCOG mixture. The addition of the diffusion term to the flow modelling provides considerable insight into the operation of a realistic reactor. 
The model predictions of the major gas phase species mole fractions before and after the addition of diffusional flow as a function of axial position are presented in Fig. 8. The upper plots show the temperature profiles (left, plug flow; right, flow with axial diffusion), and the lower plots show the gas-phase species composition. A smooth profile is observed in the model with axial diffusion. These smooth profiles are due primarily to the complete HCOG mixing with oxygen and the axial diffusion of chemical species, particularly $\mathrm{H}_{2}$, resulting in a reduction of the sharp rise in temperature near the reactor inlet. Sudden changes are observed in steam composition in both the plug flow model and axial diffusion flow model near the reactor inlet. This sudden rise in steam composition is due mainly to the two dominant exothermic reactions: $\mathrm{H}_{2}$ combustion and partial oxidation of $\mathrm{CH}_{4}$.

In both the cases, the injected $\mathrm{O}_{2}$ was consumed completely by HCOG near the reactor inlet; as a result, the mole fractions of $\mathrm{H}_{2} \mathrm{O}$ and $\mathrm{CO}_{2}$ started increasing. The water concentration reached a maximum at a reactor length of $0.1 \mathrm{~m}$ and then decreased. Downstream from the reactor, the mole fractions of $\mathrm{H}_{2} \mathrm{O}$ and $\mathrm{CH}_{4}$ decreased, and the $\mathrm{CO}$ and $\mathrm{H}_{2}$ mole fractions increased, indicating $\mathrm{CH}_{4}$ reforming. The major gas phase species reached a steady state at $0.3 \mathrm{~m}$ from the reactor inlet. This indicates that the major reactions during the HCOG reforming by partial oxidation and steam reforming were nearly complete.

The pilot-scale measurements of run 11 were used to validate the diffusional flow model. Numerical simulations were performed with boundary and inlet conditions identical to those of run 11 . The predictive capabilities of the plug flow and axial diffusion models are compared in Figure 9, where the predicted values were plotted against measured ones. Significant improvements were observed mainly in the $\mathrm{CH}_{4}$ 
predictions, and slight improvements in the $\mathrm{H}_{2}, \mathrm{CO}$, and $\mathrm{CO}_{2}$ mole fraction predictions at the reactor exit. For example, in one of the pilot scale runs, the $\mathrm{CH}_{4}$ predictions by the axial diffusion model and plug flow model were 1.15 mol.\% and 0.68 mol.\%, respectively. The experimentally measured value was 1.33 mol.\%. The improvements in the prediction arose mainly from a reduction in the sharp rise in temperature at the reactor entrance caused by the axial diffusion of the species.

Figure 10 shows the comparison between plug flow and axial diffusion model predictions for the dry gas flow rate versus those measured at the reactor exit. The model predictions of an axial diffusion model were very closed to the pilot scale measurements. The disturbances in the model predictions needs further research to examine our assumptions. The reforming features of HCOG may be captured more precisely by using multi-dimensional simulations. Further study will include CFD model coupled with detailed chemical kinetic model.

\section{Conclusions}

This study offers a new numerical approach for predicting the axial temperature profile for HCOG reforming by partial oxidation. One-dimensional reactor models were developed that considered the heat loss from the reactor wall to the surroundings (plug flow) and axial diffusion, validated with pilot-scale HCOG reforming with partial oxidation measurements. In the plug flow simulations, an ignition temperature option was used initially to calculate the reaction rates, and then the reaction rates were calculated using the gas-phase temperature. The overall heat transfer coefficient for heat losses from the reactor was optimised empirically at $4 \mathrm{~W} / \mathrm{m}^{2} \cdot \mathrm{K}$; with this value, the experimental axial temperature profiles of the HCOG pilot-scale runs were reproduced 
well. In the numerical simulations, a sharp rise in temperature was observed; this behaviour was unrealistic in a real reactor. The model predictions were validated exhaustively with 19 pilot-scale runs of axial temperature profiles along with the composition of the major gas phase species $\left(\mathrm{H}_{2}, \mathrm{CO}, \mathrm{CO}_{2}\right.$ and $\left.\mathrm{CH}_{4}\right)$ and total dry gas flow rates. With the plug flow model, the ratios of gas composition (vol.\%) between predicted and measured values were ranged 0.96-1.02, 1.11-1.29, 0.65-0.9, and 0.090.94 for $\mathrm{H}_{2}$, $\mathrm{CO}, \mathrm{CO}_{2}$, and $\mathrm{CH}_{4}$, respectively. Marked deviation was observed between the $\mathrm{CH}_{4}$ model predictions and pilot-scale tests. A global sensitivity analysis was used to identify the temperature-sensitive reactions. The reaction of $\mathrm{H}_{2}$ with $\mathrm{OH}$ forming $\mathrm{H}_{2} \mathrm{O}$ and $\mathrm{H}$ was the reaction most responsible for the under-prediction of $\mathrm{H}_{2}$ and $\mathrm{CO}_{2}$ and over-prediction of the $\mathrm{CO}$ mole fractions. The $\mathrm{CH}_{4}$ decomposition reaction giving $\mathrm{CH}_{3}$ and $\mathrm{H}$ was more temperature sensitive and was responsible for the $\mathrm{CH}_{4}$ underprediction. The addition of a diffusion flow term in the reactor model provides considerable insight into the operation of a realistic reactor. Improved predictions are obtained with a 1D flow model with axial diffusion. The improvements in the model predictions are due primarily to the improved temperature predictions by accounting for axial diffusion in the flow model.

\section{Acknowle dgement}

Part of this research was funded by the Ministry of Education, Science, Sports and Culture Grant-in-Aid for Young Scientists A (No. 23686112), Network Joint Research

Center for Materials and Devices, and the MOST-JST, Strategic International Collaborative Research Program SICORP. 


\section{References}

[1] T. Aramaki, Status of the coke oven gas in Japan, J.Jpn.Inst. Energy. 85 (2006) 342-347.

[2] K. Miura, M. Kawase, H. Nakagawa, R. Ashida, T. Nakai, T. Ishikawa, Conversion of Tar in Hot Coke Oven Gas by Pyrolysis and Steam Reforming., J. Chem. Eng. Japan. 36 (2003) 735-741.

[3] A. Jess, Catalytic upgrading of tarry fuel gases: A kinetic study with model components, Chem. Eng. Process. Process Intensif. 35 (1996) 487-494.

[4] A. Jess, Mechanisms and kinetics of thermal reactions of aromatic hydrocarbons from pyrolysis of solid fuels, 75 (1996) 1441-1448.

[5] J. Kirton, T. Crisp, The analysis of organic oven emissions in coke, Fuel. 70 (1991) 1383-1389.

[6] Y. Zhang, Q. Li, P. Shen, Y. Liu, Z. Yang, W. Ding, et al., Hydrogen amplification of coke oven gas by reforming of methane in a ceramic membrane reactor, Int. J. Hydrogen Energy. 33 (2008) 3311-3319.

[7] M. Kong, Q. Yang, J. Fei, X. Zheng, Experimental study of Ni/MgO catalyst in carbon dioxide reforming of toluene, a model compound of tar from biomass gasification, Int. J. Hydrogen Energy. 37 (2012) 13355-13364.

[8] W. Tao, H. Cheng, W. Yao, X. Lu, Q. Zhu, G Li, et al., Syngas production by $\mathrm{CO} 2$ reforming of coke oven gas over $\mathrm{Ni} / \mathrm{La} 2 \mathrm{O} 3-\mathrm{ZrO} 2$ catalysts, Int. J. Hydrogen Energy. (2014) 1-9.

[9] S.G Shen, P.P. Chen, A.Q. Li, H.F. Qin, B.B. Li, Y.P. Ren, Effect of three processes on CO 2 and $\mathrm{O} 2$ simultaneously reforming of coke oven gas to syngas, Chem. Eng. Process. Process Intensif. 75 (2014) 75-80.

[10] J. Zhang, X. Zhang, Z. Chen, L. Li, Thermodynamic and kinetic model of reforming coke-oven gas with steam, Energy. 35 (2010) 3103-3108.

[11] M. Onozaki, K. Watanabe, T. Hashimoto, H. Saegusa, Y. Katayama, Hydrogen production by the partial oxidation and steam reforming of tar from hot coke oven gas, Fuel. 85 (2006) 143-149.

[12] M. Hashimoto, T ; Onozaki, Reforming of hot coke oven gas, Jpn. Inst. Energy. 85 (2006) 364-370.

[13] K. Norinaga, H. Yatabe, M. Matsuoka, J. Hayashi, Application of an Existing Detailed Chemical Kinetic Model to a Practical System of Hot Coke Oven Gas 
Reforming by Noncatalytic Partial Oxidation, Ind. Eng. Chem. Res. 49 (2010) 10565-10571.

[14] J.N. Kuhn, N. Lakshminarayanan, U.S. Ozkan, Effect of hydrogen sulfide on the catalytic activity of Ni-YSZ cermets, J. Mol. Catal. 282 (2008) 9-21.

[15] S. Appari, V.M. Janardhanan, R. Bauri, S. Jayanti, Deactivation and regeneration of Ni catalyst during steam reforming of model biogas: An experimental investigation, Int. J. Hydrogen Energy. 39 (2014) 297-304.

[16] H.Y. Wang, A.C. Lua, Deactivation and kinetic studies of unsupported $\mathrm{Ni}$ and $\mathrm{Ni}$ Co-Cu alloy catalysts used for hydrogen production by methane decomposition, Chem. Eng. J. 243 (2014) 79-91.

[17] M. Guisnet, P. Magnoux, Catalyst Deactivation 1994, Proceedings of the 6th International Symposium, Elsevier, 1994.

[18] M. Guisnet, P. Magnoux, Coking and Deactivation of Zeolites Influence of the Pore Structure, Appl. Catal. 54 (1989) 1-27.

[19] M. Halabi, M. Decroon, J. Vanderschaaf, P. Cobden, J. Schouten, Modeling and analysis of autothermal reforming of methane to hydrogen in a fixed bed reformer, Chem. Eng. J. 137 (2008) 568-578.

[20] T.P. Tiemersma, T. Kolkman, J. a. M. Kuipers, M. van Sint Annaland, A novel autothermal reactor concept for thermal coupling of the exothermic oxidative coupling and endothermic steam reforming of methane, Chem. Eng. J. 203 (2012) 223-230.

[21] K. Norinaga, V.M. Janardhanan, O. Deutschmann, Modeling of Pyrolysis of Ethylene , Acetylene , and Propylene at $1073-1373 \mathrm{~K}$ with a Plug-Flow Reactor Model, Int. J. Chem. Kinet. 40 (2007) 199-208.

[22] C.Y. Sheng, A.M. Dean, Importance of Gas-Phase Kinetics within the Anode Channel of a Solid-Oxide Fuel Cell, J. Phys. Chem. A. 108 (2004) 3772-3783.

[23] K. Norinaga, O. Deutschmann, Detailed kinetic modeling of gas-phase reactions in the chemical vapor deposition of carbon from light hydrocarbons, Ind. Eng. Chem. Res. 46 (2007) 3547-3557.

[24] A. Bittante, J. García-Serna, P. Biasi, F. Sobrón, T. Salmi, Residence time and axial dispersion of liquids in Trickle Bed Reactors at laboratory scale, Chem. Eng. J. 250 (2014) 99-111.

[25] H. Richter, J.B. Howard, Formation and consumption of single-ring aromatic hydrocarbons and their precursors in premixed acetylene, ethylene and benzene flames, Phys. Chem. Chem. Phys. 4 (2002) 2038-2055. 
[26] R.B. Bird, W.E. Stewart, E.N. Lightfoot, Transport Phenomena, Revised 2nd Edition, 2nd ed., John Wiley \& Sons, Inc., 2006.

[27] H. Richter, J.B. Howard, Formation and consumption of single-ring aromatic hydrocarbons and their precursors in premixed acetylene, ethylene and benzene flames, Phys. Chem. Chem. Phys. 4 (2002) 2038-2055.

[28] K. Norinaga, Y. Sakurai, R. Sato, J. Hayashi, Numerical simulation of thermal conversion of aromatic hydrocarbons in the presence of hydrogen and steam using a detailed chemical kinetic model, Chem. Eng. J. 178 (2011) 282-290.

[29] K. Norinaga, J. Hayashi, Numerical Simulation of the Partial Oxidation of Hot Coke Oven Gas with a Detailed Chemical Kinetic Model †, Energy \& Fuels. 24 (2010) 165-172.

[30] P. Deuflhard, E. Hairer, J. Zugck, Numerische Mathematik One-step and Extrapolation Methods for Differential-Algebraic Systems, Springer-Verlag, Germany, 1987.

[31] B. Hindmarsh, Grant, Lee, Serban, Shumaker, Woodward, SUNDIALS: Suite of nonlinear and differential/algebra ic equation solvers, ACM Trans. Math. Softw. 31 (2005) 363-396.

[32] O. Deutschmann, S. Tischer, S. Kleditzsch, V. Janardhanan, C. Correa, D. Chatterjee, et al., DETCHEM Software package, 2.4 ed., Germany, 2013. www.detchem.com.

[33] J. Warnatz and U. Maas and R. W. Dibble, Combustion, Physical and Chemical Fundamentals, Modeling and Simulation, Experiments, Pollutant Formation, 3rd ed., Springer-Verlag Berlin Heidelberg GmbH, 2001.

[34] O. Deutschmann, L.D. Schmidt, Modeling the partial oxidation of methane in a short-contact-time reactor, AIChE J. 44 (1998) 2465-2477. 


\section{Graphical Abstract}
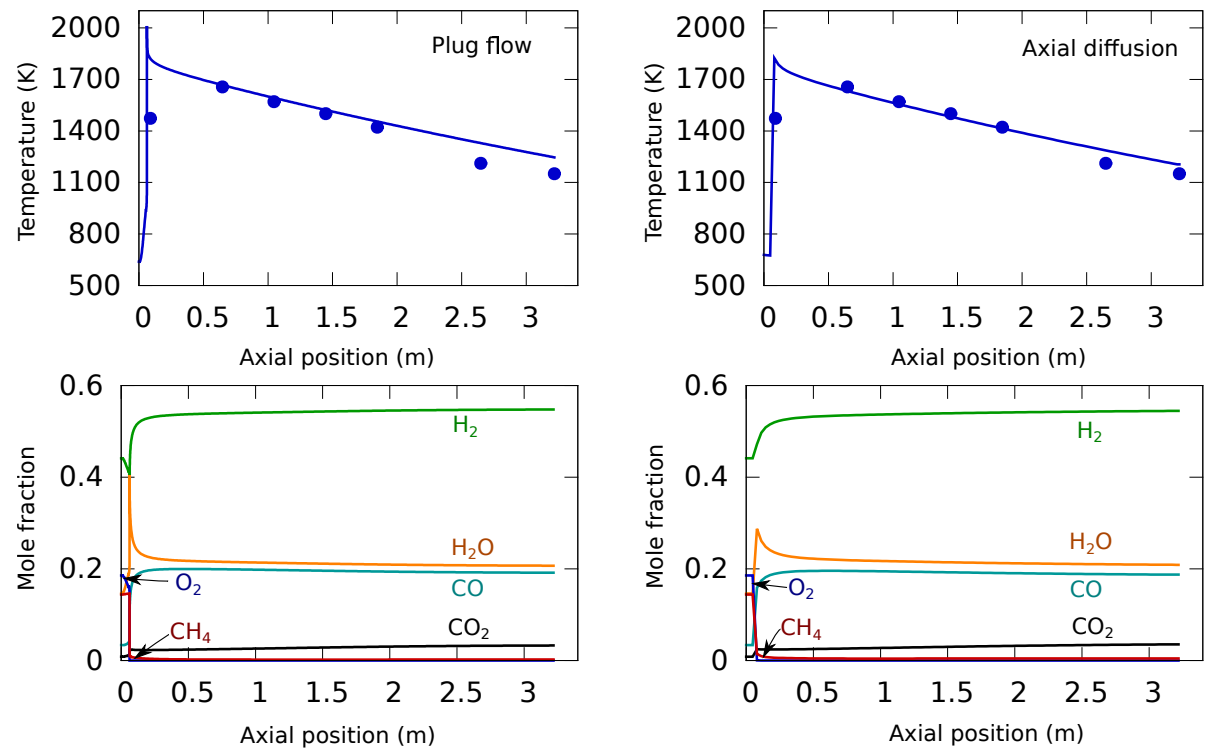

Comparison of the temperature (top) and mole fraction (bottom) profiles without (left) and with (right) diffusional flow along the reactor axis during HCOG reforming via partial oxidation (run 11). The symbols indicate experimentally measured values, and the solid lines represent model predictions. The HCOG and $\mathrm{O}_{2}$ flow rates are $62.9 \mathrm{Nm}^{3} / \mathrm{h}$ and $17.6 \mathrm{Nm}^{3} / \mathrm{h}$, respectively. 


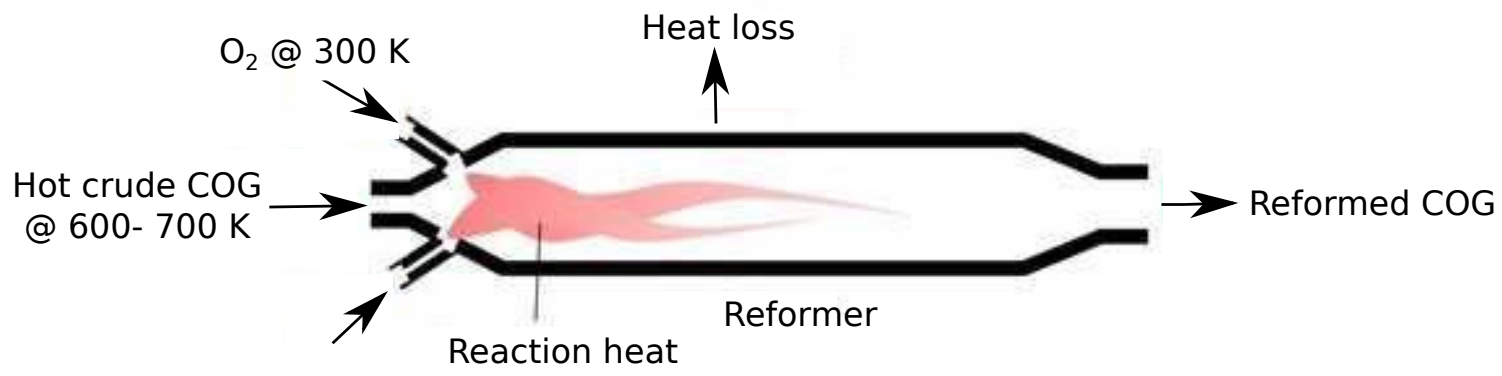

Figure 1: Schematic representation of the pilot-scale HCOG reformer.

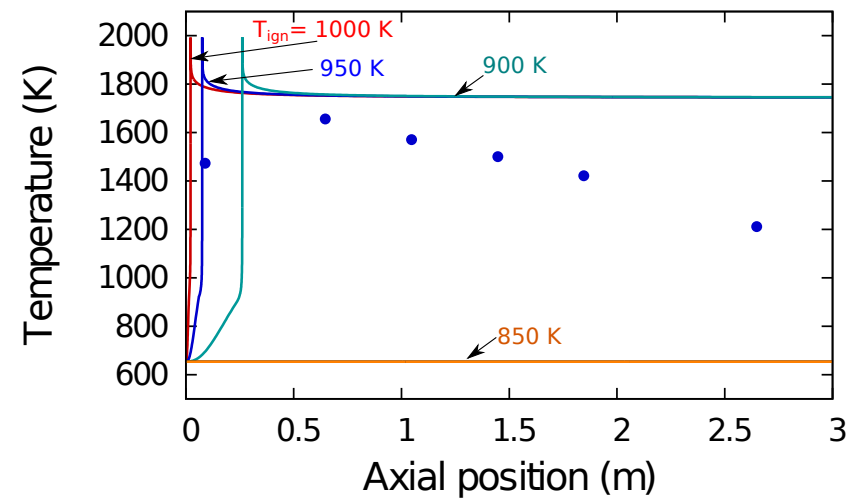

Figure 2: The effect of ignition temperature on the temperature distribution along the axial length of reactor. The symbols indicate experimentally measured values, and the solid lines represent model predictions. 


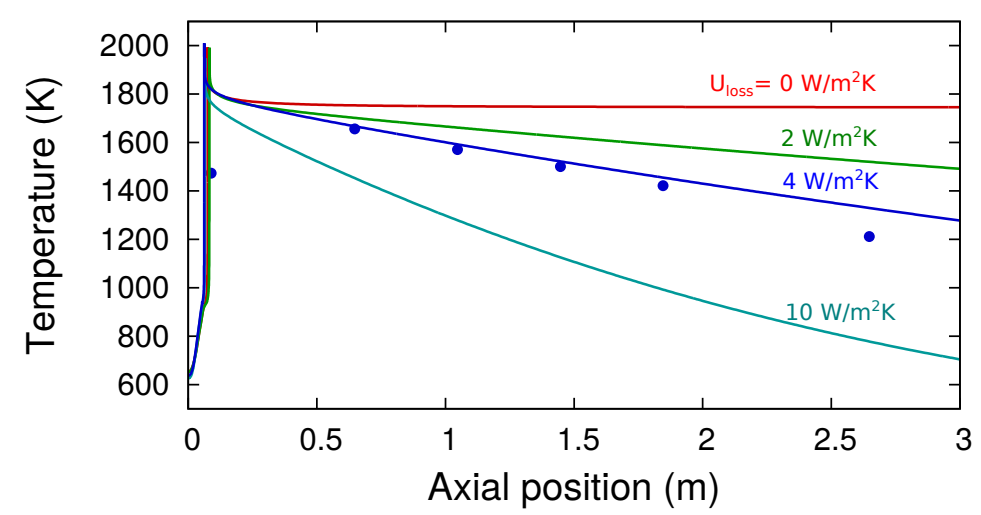

Figure 3: The effect of the overall heat transfer coefficient (heat losses from the reactor) on the temperature distribution along the axial length of the reactor. These plots were made with ignition at $950 \mathrm{~K}$. The symbols indicate experimentally measured values, and the solid lines represent model predictions.

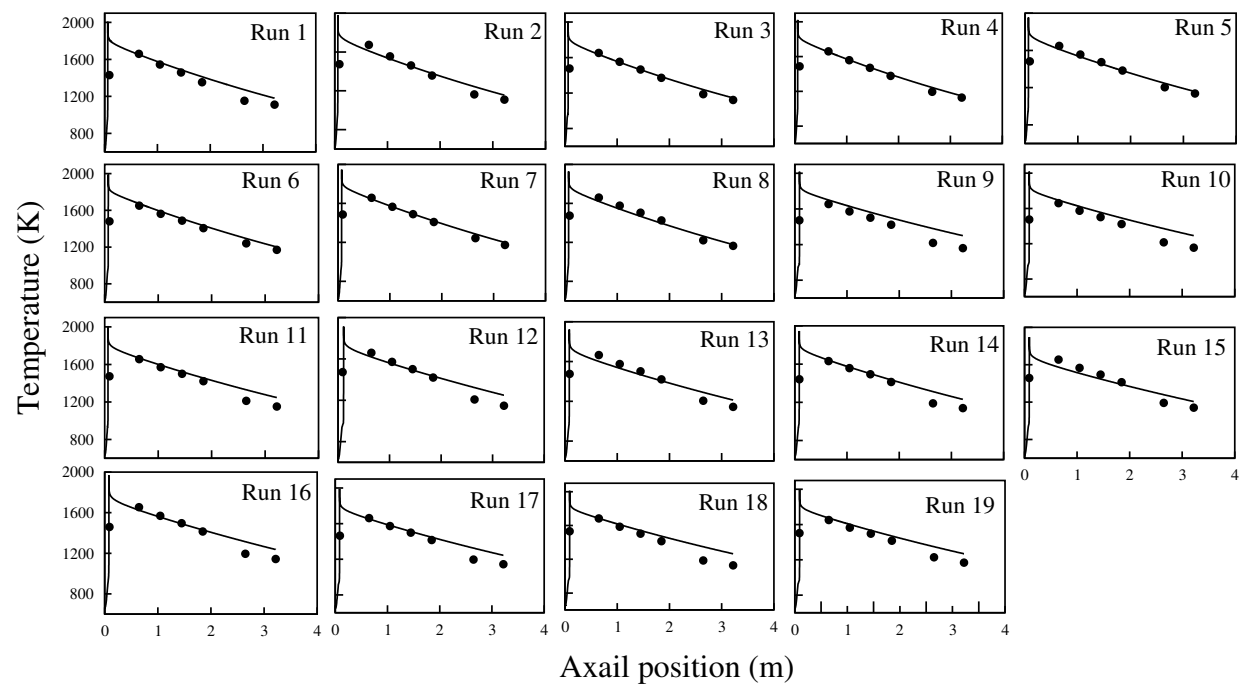

Figure 4: Comparison of the model predictions and experimental observations of temperatures along the axial length of the reactor. The symbols indicate experimentally measured values, and the solid lines represent model predictions. 


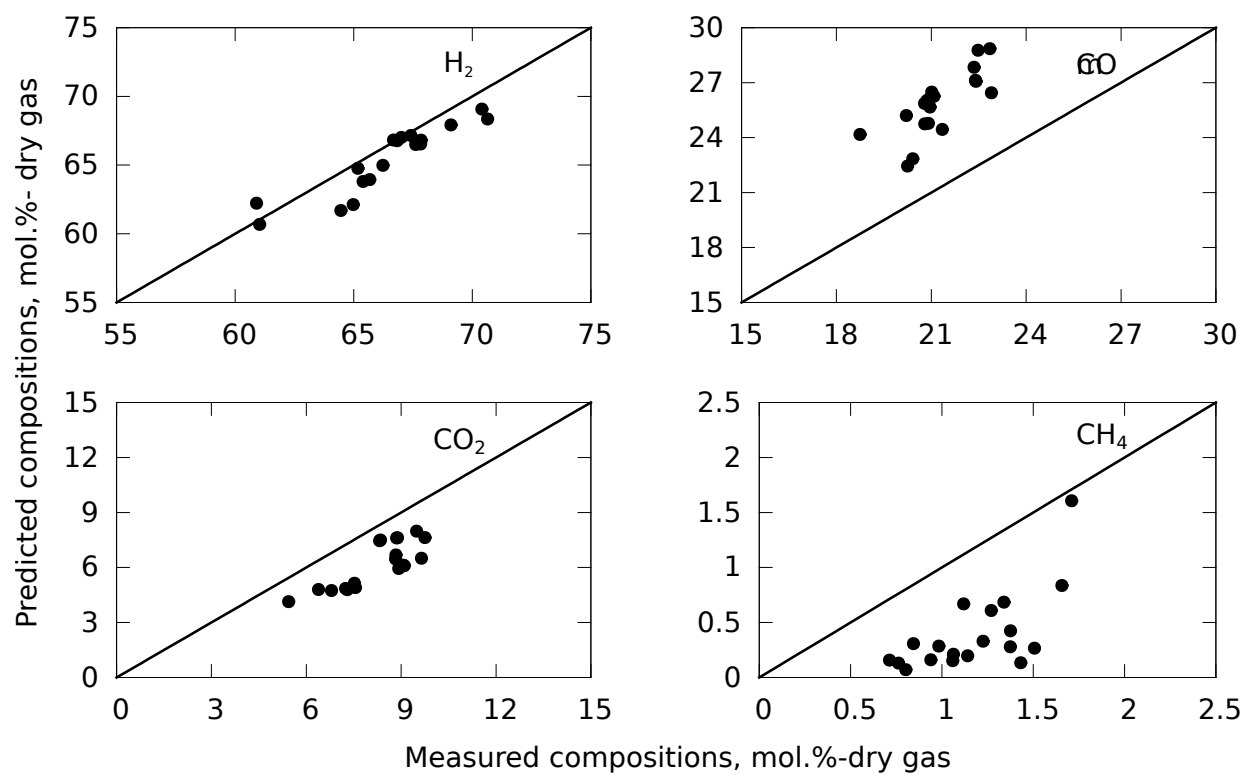

Figure 5: Major gas compositions at the reformer outlet predicted by the plug flow numerical simulations versus those measured by the pilot-scale tests for HCOG reforming with non-catalytic partial oxidation. 


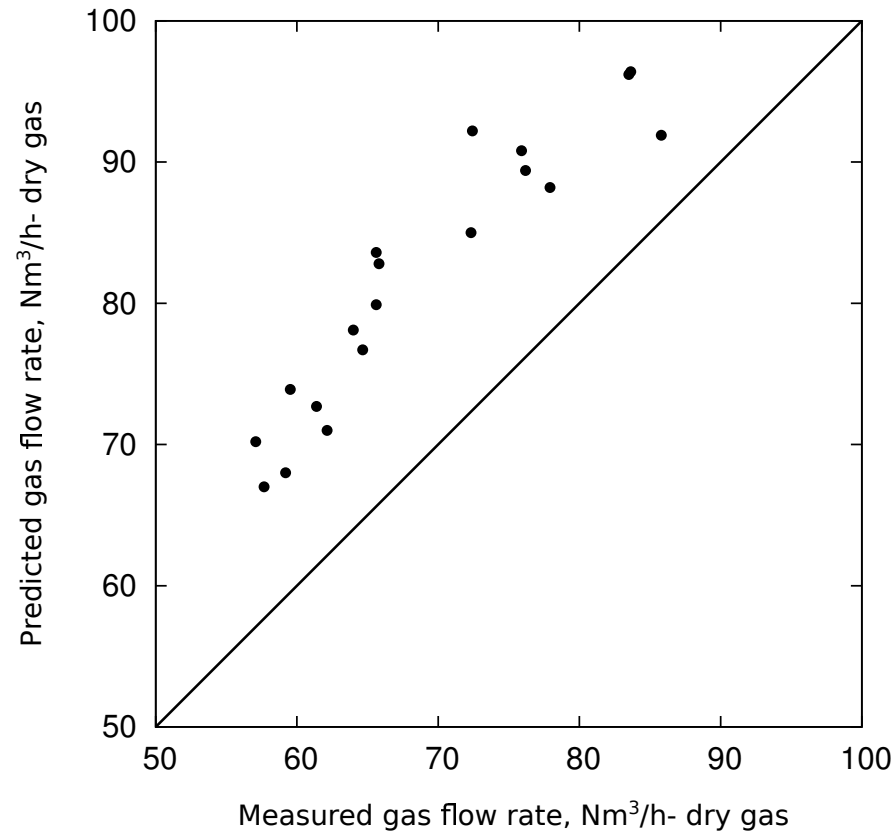

Figure 6: Dry gas flow rates at the reformer outlet predicted by the plug flow numerical simulation versus those measured in the pilot-scale tests of HCOG reforming with non-catalytic partial oxidation. 

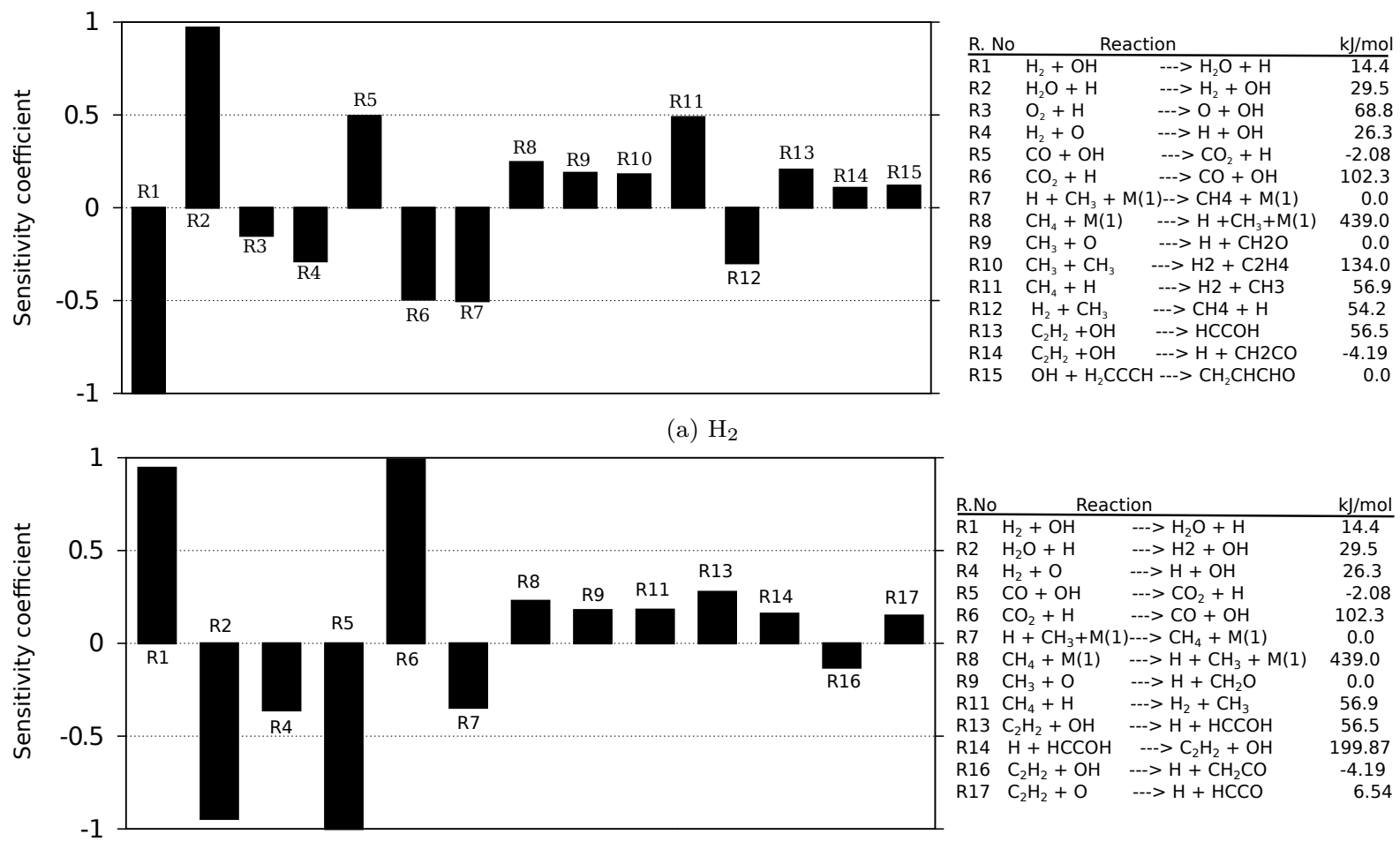

(b) $\mathrm{CO}$

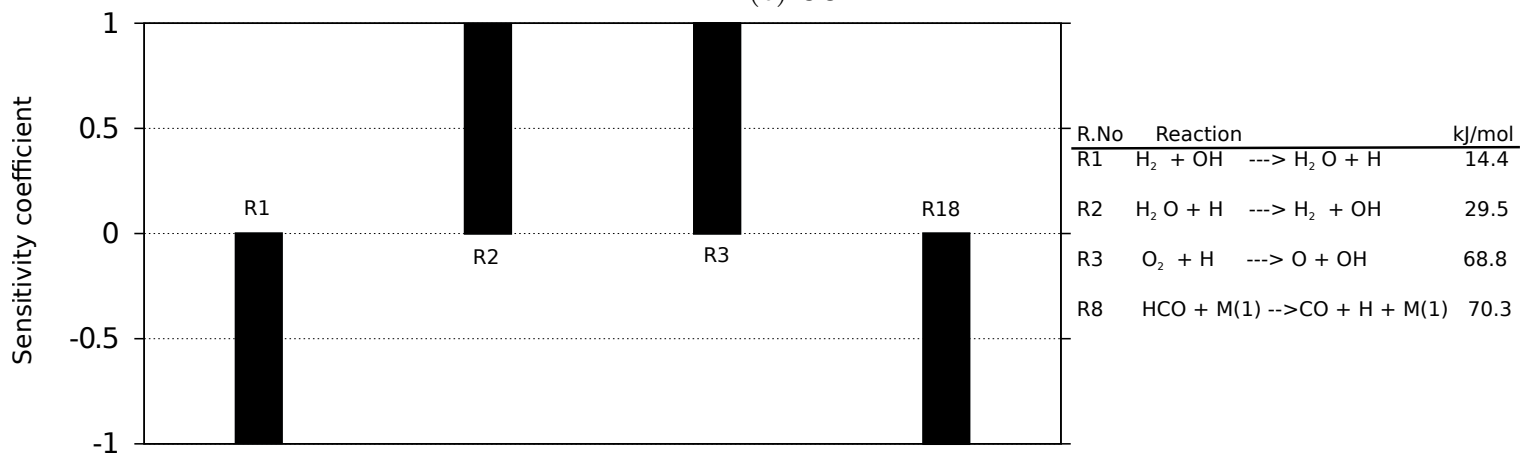

(c) $\mathrm{CO}_{2}$
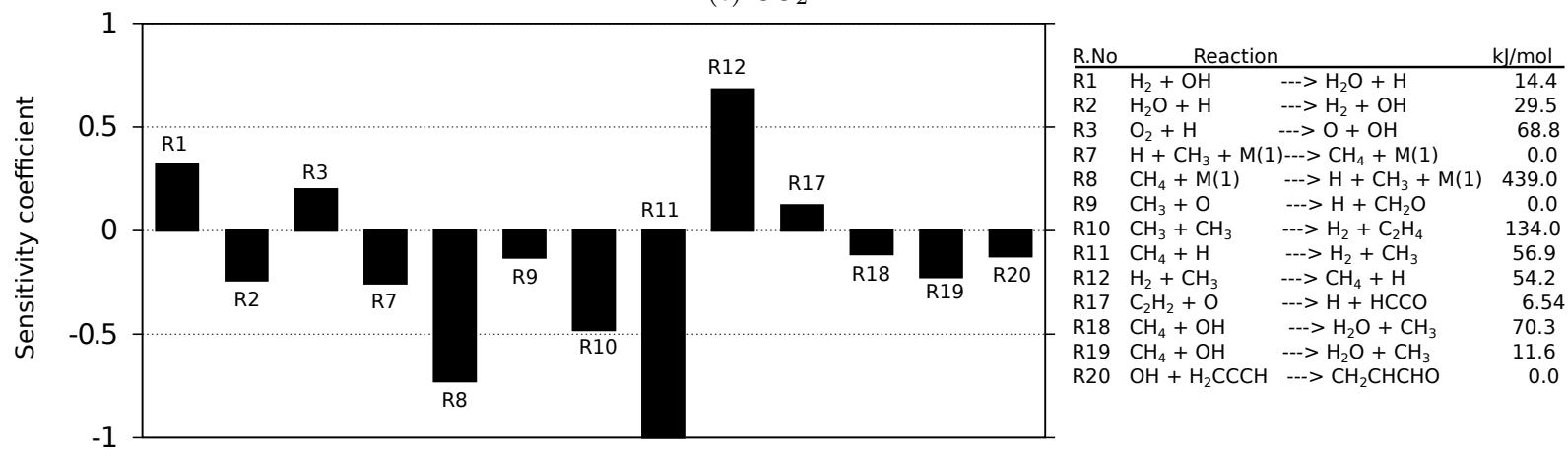

(d) $\mathrm{CH}_{4}$

5

Figure 7: Global sensitivity analysis of the major gas phase species $\mathrm{H}_{2}, \mathrm{CO}$, $\mathrm{CO}_{2}$, and $\mathrm{CH}_{4}$. 

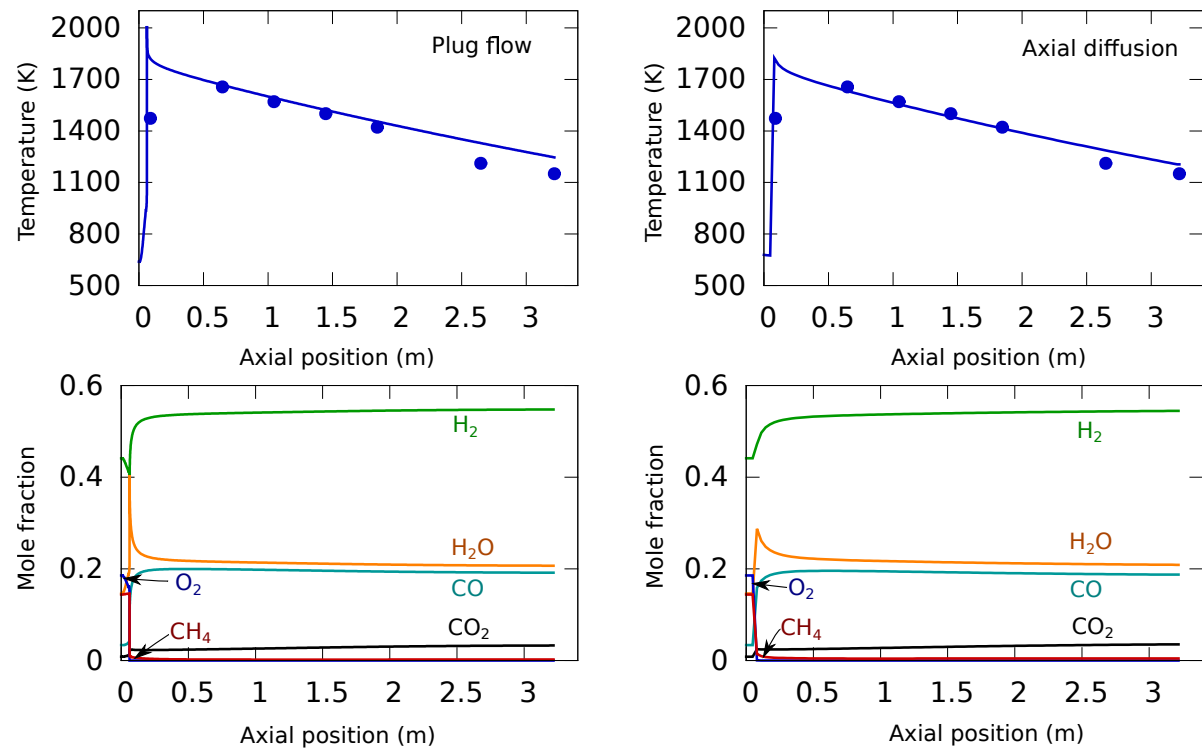

Figure 8: Comparison of the temperature (top) and mole fraction (bottom) profiles without (left) and with (right) diffusional flow along the reactor axis during HCOG reforming with partial oxidation (run 11). The symbols indicate experimentally measured values, and the solid lines represent model predictions. The $\mathrm{HCOG}$ and $\mathrm{O}_{2}$ flow rates are $62.9 \mathrm{Nm}^{3} / \mathrm{h}$ and $17.6 \mathrm{Nm}^{3} / \mathrm{h}$, respectively. 


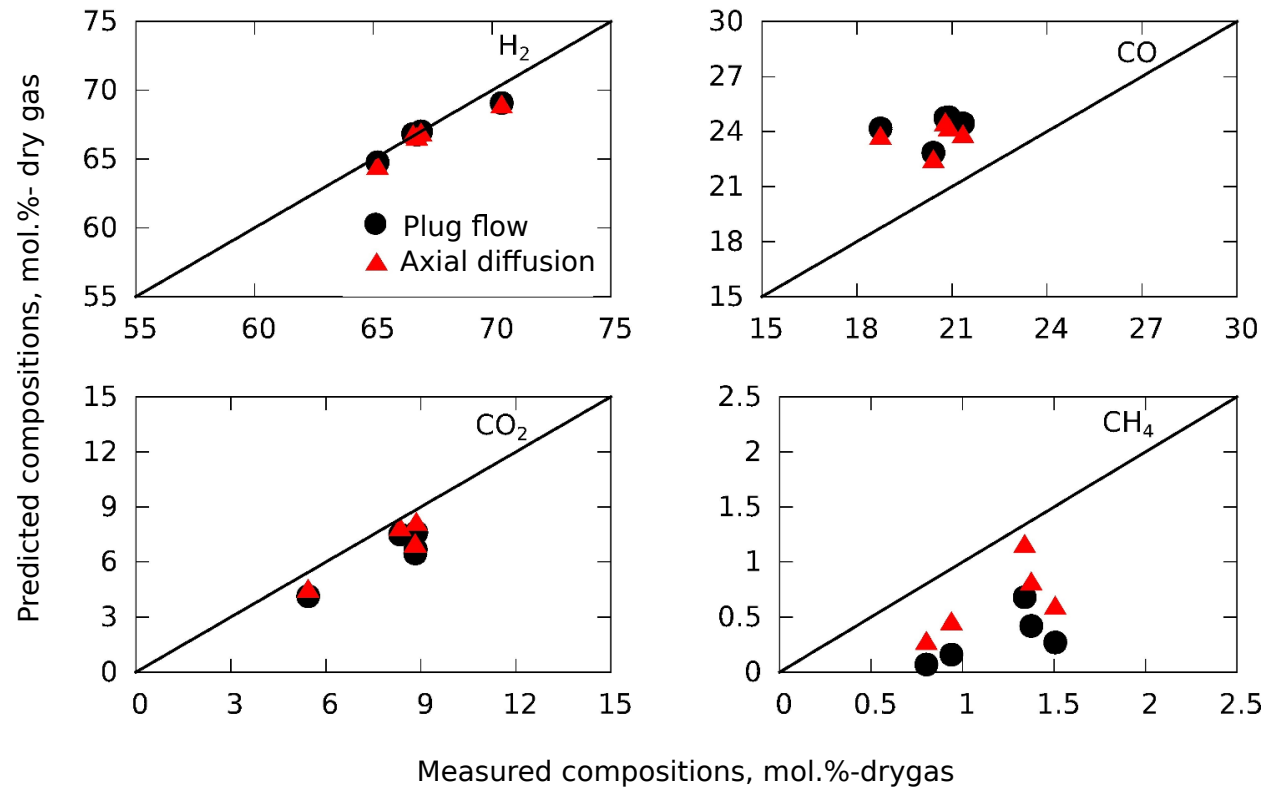

Figure 9: Comparision of the reformed gas compositions predicted by the plug flow model and one dimensional flow with axial diffusion model with those measured by the pilot-scale tests for HCOG reforming with non-catalytic partial oxidation. 


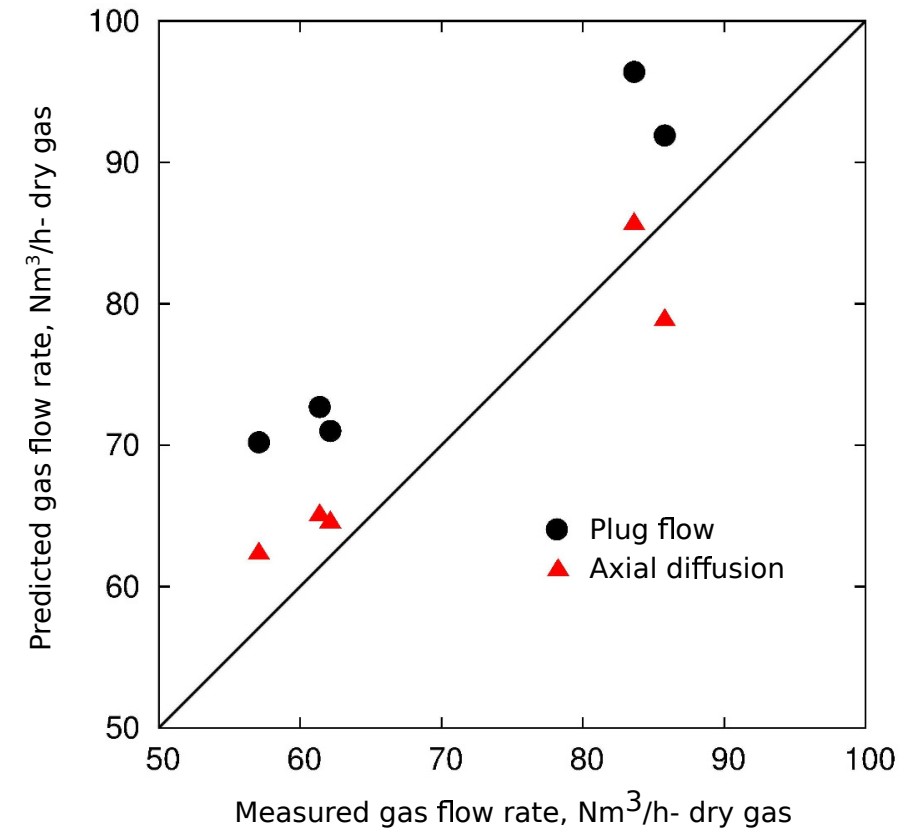

Figure 10: Comparision of the reformed gas flow rates predicted by the plug flow model and one dimensional flow with axial diffusion model with those measured by the pilot-scale tests of HCOG reforming with non-catalytic partial oxidation. 


\section{Table 1}

Composition of the feed HCOG for numerical simulation (run 11).

\begin{tabular}{|c|c|}
\hline Compounds & $\begin{array}{l}\text { Mole } \\
\text { fraction }\end{array}$ \\
\hline $\mathrm{H}_{2}$ & 4.413E-01 \\
\hline $\mathrm{CH}_{4}$ & 1.439E-01 \\
\hline $\mathrm{C}_{2} \mathrm{H}_{4}$ & 7.261E-03 \\
\hline $\mathrm{C}_{2} \mathrm{H}_{6}$ & 2.602E-03 \\
\hline $\mathrm{CO}$ & 3.374E-02 \\
\hline $\mathrm{CO}_{2}$ & 8.276E-03 \\
\hline $\mathrm{N}_{2}$ & 2.279E-02 \\
\hline $\mathrm{O}_{2}$ & $1.855 \mathrm{E}-01$ \\
\hline $\mathrm{H}_{2} \mathrm{O}$ & $1.461 \mathrm{E}-01$ \\
\hline benzene & 3.362E-03 \\
\hline toluene & 4.034E-04 \\
\hline xylene & $0.000 \mathrm{E}+00$ \\
\hline styrene & $1.468 \mathrm{E}-04$ \\
\hline phenol & $3.211 \mathrm{E}-04$ \\
\hline indene & $4.221 \mathrm{E}-04$ \\
\hline naphthalene & 2.346E-03 \\
\hline 2-methylnaphthalene & 2.052E-04 \\
\hline 1-methylnaphthalene & $9.145 \mathrm{E}-05$ \\
\hline acenaphthylene & $1.616 \mathrm{E}-04$ \\
\hline acenaphthene & 3.305E-05 \\
\hline fluorine & 1.015E-04 \\
\hline
\end{tabular}




\begin{tabular}{ll} 
phenanthrene & $3.293 \mathrm{E}-04$ \\
anthracene & $8.282 \mathrm{E}-05$ \\
cyclopenta[def]phenanthrene & $1.293 \mathrm{E}-05$ \\
2-phenylnaphthalene & $6.022 \mathrm{E}-06$ \\
fluoranthene & $1.329 \mathrm{E}-04$ \\
acephnanthrylene & $5.213 \mathrm{E}-06$ \\
aceanthrylene & $4.344 \mathrm{E}-06$ \\
pyrene & $9.122 \mathrm{E}-05$ \\
benzo[a]fluorine & $7.312 \mathrm{E}-06$ \\
\hline cyclopenta[cd]pyrene & $2.330 \mathrm{E}-06$ \\
\hline benz[a]anthracene & $3.618 \mathrm{E}-05$ \\
\hline chrysene & $3.848 \mathrm{E}-05$ \\
\hline benzo[b]fluoranthene & $2.925 \mathrm{E}-05$ \\
\hline benzo[e]pyrene & $2.228 \mathrm{E}-05$ \\
\hline benzo[a]pyrene & $2.368 \mathrm{E}-05$ \\
\hline
\end{tabular}

